\title{
Post-mortem computed tomography coaxial cutting needle biopsy to facilitate the detection of bacterioplankton using PCR probes as a diagnostic indicator for drowning
}

\author{
Guy N. Rutty ${ }^{1}$ - Christopher Johnson ${ }^{1}$ - Jasmin Amoroso ${ }^{1}$ - Claire Robinson ${ }^{2}$. \\ Carina J. Bradley ${ }^{3} \cdot$ Bruno Morgan $^{4}$
}

Received: 7 March 2016 / Accepted: 11 October 2016/Published online: 5 November 2016

(C) The Author(s) 2016. This article is published with open access at Springerlink.com

\begin{abstract}
We report for the first time the use of coaxial cutting needle biopsy, guided by post-mortem computed tomography (PMCT), to sample internal body tissues for bacterioplankton PCR analysis to investigate drowning. This technical report describes the biopsy technique, the comparison of the needle biopsy and the invasive autopsy sampling results, as well as the PMCT and autopsy findings. By using this new biopsy sampling approach for bacterioplankton PCR, we have developed on previous papers describing the minimally invasive PMCT approach for the diagnosis of drowning. When such a system is used, the operator must take all precautions to avoid contamination of the core biopsy samples due to the sensitivity of PCR-based analytic systems.
\end{abstract}

Keywords Forensic $\cdot$ Post-mortem computed tomography · PMCT · Coaxial cutting needle biopsy · Drowning ·

Bacterioplankton $\cdot$ Real-time PCR

Guy N. Rutty and Bruno Morgan contributed equally to this work.

Guy N. Rutty

gnr3@le.ac.uk

Carina J. Bradley

carina.bradley@uhl-tr.nhs.uk

1 East Midlands Forensic Pathology Unit, University of Leicester, Robert Kilpatrick Building, Leicester LE2 7LX, UK

2 Imaging Department, University Hospitals of Leicester, Leicester Royal Infirmary, Leicester LE2 7LX, UK

3 Clinical Microbiology, Empath Pathology Services, University Hospitals of Leicester NHS Trust, Leicester Royal Infirmary, Leicester LE1 5WW, UK

4 Radiology Department, University of Leicester, Robert Kilpatrick Building, Leicester LE2 7LX, UK

\section{Introduction}

Post-mortem cross-sectional imaging is playing an increasing role as a diagnostic adjunct or a replacement to invasive autopsy, and a number of authors have drawn attention to the post-mortem computed tomography (PMCT) observations associated with drowning. They have reported fluid within the paranasal sinuses, fluid within the airways, chest and abdominal structures, changes to the lung parenchyma and the presence of haemodilution observed in the right and left atria and spleen [1-10]. Although Raux et al. have suggested an algorithm to diagnose drowning on PMCT [4], the findings of PMCT remain non-specific [9], and therefore, PMCT remains only an adjunct to invasive autopsy in suspected drowning.

The concept of using polymerase chain reaction (PCR) methods to amplify bacteria genes to aid the diagnosis of drowning was originally reported by Suto et al. in 2007 [11]. In 2012, Uchiyama et al. reported the use of real-time PCR assays with TaqMan probes for bacterioplankton to differentiate between freshwater and marine bacterioplankton DNA and provide a molecular diagnostic test to assist in the diagnosis of drowning [12]. More recently, Rutty et al. reported their experience of the use of bacterioplankton PCR probes for the diagnosis of drowning within England [13]. The diagnostic material required for the PCR tests has previously been obtained through invasive autopsy.

We propose that these samples could be obtained using coaxial cutting needle biopsies guided by PMCT [14]. In this case report, we demonstrate the successful use of this technique for the first time in order to help other teams who are using PMCT to investigate bodies discovered immersed in water. We discuss the potential for DNA contamination during coaxial PMCT needle biopsy sampling. 


\section{Materials and method}

\section{Case summary}

An 81-year-old male with a known history of depression and previous attempted suicide by slashing his wrists and hanging, took a taxi from his home to a fairly remote location near to a river. He failed to return home, and on the 8th day, a body was located, caught up in foliage overhanging the swollen river. The body was subsequently identified to be the missing male. A medico-legal autopsy was authorised by Her Majesty's Senior Coroner for the jurisdiction of the death. This was undertaken 6 days after the discovery of the body (14 days after the disappearance). On the day prior to the autopsy, the body underwent PMCT examination.

The deceased was consented for PMCT research, including core needle biopsy, pulmonary ventilation and targeted limb vessel angiography in accordance with previously published ethics and consenting procedures [15] by the relatives of the deceased. The ventilation and angiography procedures were undertaken following core needle biopsy sampling and do not form part of this report.

\section{PMCT needle biopsy samples}

Prior to needle biopsy, a whole body PMCT scan was performed using a Toshiba Aquilion CXL 128 slice scanner $(120 \mathrm{kVp}, 300 \mathrm{~mA}$ and $128 \times 0.5-\mathrm{mm}$ slice thickness, matrix $512 \times 512$ ) reconstructed to $1 \mathrm{~mm}$ (head and neck) or $2 \mathrm{~mm}$ (chest, abdomen, pelvis and legs) slices.

Cutting needle biopsies were undertaken using a technique similar to clinical radiology practice [14]. A co-axial technique was used to avoid cellular contamination of the biopsy needle from the skin. A new needle was used for each biopsy (16G Coaxial Temno Evolution biopsy needle, Carefusion, McGaw Park, IL, USA). Ten-millimetre-long samples were taken, in order from the left lung, spleen, left kidney and brain.

The first sample obtained was from the left lung. The desired biopsy location was selected from the images, and a radio-opaque skin marker strip was placed on the adjacent chest wall after cleaning with alcohol. The geometry tools on the CT workstation were used to determine the angle of approach and depth of insertion of the needle from the skin marker (Fig. 1a). The pathologist then inserted the needle using these parameters (Fig. 1b). Prior to sampling, the needle position was checked by PMCT. Cutting needle biopsy was then performed. The same procedure was then repeated for the spleen (Fig. 2a) and the left kidney (Fig. 2b). In the case of the spleen, the operator should access the inferior aspect of the spleen or insert the needle at an oblique angle to avoid crossing the pleura.

The brain was sampled by inserting the needle through the right nasal cavity at an approximate angle of $45^{\circ}$. This enabled
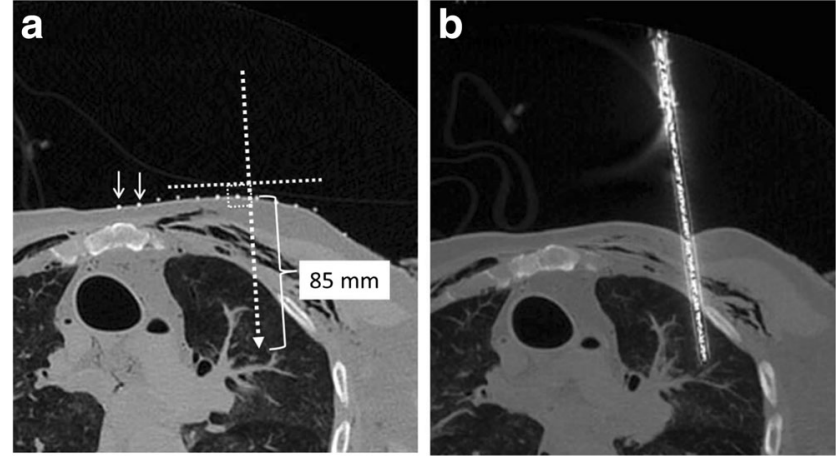

Fig. 1 a The radio-opaque skin marker strip is placed on the left chest wall (small arrows), and the angle of approach and depth of insertion of the needle can be planned using the geometry tools on the CT workstation. The needle is then be inserted at the planned angle and distance and a further set of CT images (b) are acquired to confirm the location of the needle prior to biopsy

the needle to breach the right cribriform plate and pass into the substance of the right cerebral hemisphere. Again, prior to sampling, the position of the needle was checked on PMCT (Fig. 2c).

All samples were placed into separate sterile containers with no preservative. These were placed into a refrigerator at $4{ }^{\circ} \mathrm{C}$ before being processed in the Clinical Microbiology laboratory at Leicester Royal Infirmary.

\section{Reference water sample}

A reference river water sample was obtained from the point where the body was recovered. This was provided to the Clinical Microbiology laboratory with the tissue samples.

\section{Autopsy}

A full invasive autopsy was undertaken the following day by a senior trainee forensic pathologist working to national forensic pathology guidelines [16]. Repeat samples for bacterioplankton PCR were taken from the approximate area of the core needle biopsy sites within the brain, left lung, left kidney and spleen at autopsy. For each case, a new scalpel blade and a clean, different pair of forceps were used for sampling and tissue handling. All samples were again placed into separate sterile universal containers with no preservative. These were placed into a refrigerator at $4{ }^{\circ} \mathrm{C}$ before being processed in the Clinical Microbiology laboratory at Leicester Royal Infirmary.

\section{DNA isolation, PCR investigation and assay analytical sensitivity and linearity}

The bacterioplankton PCR procedures used for the investigation of this case followed the methods and materials 
Fig. 2 PMCT images of the angle and position of the cutting needle prior to sampling of the a spleen, $\mathbf{b}$ left kidney and $\mathbf{c}$ brain
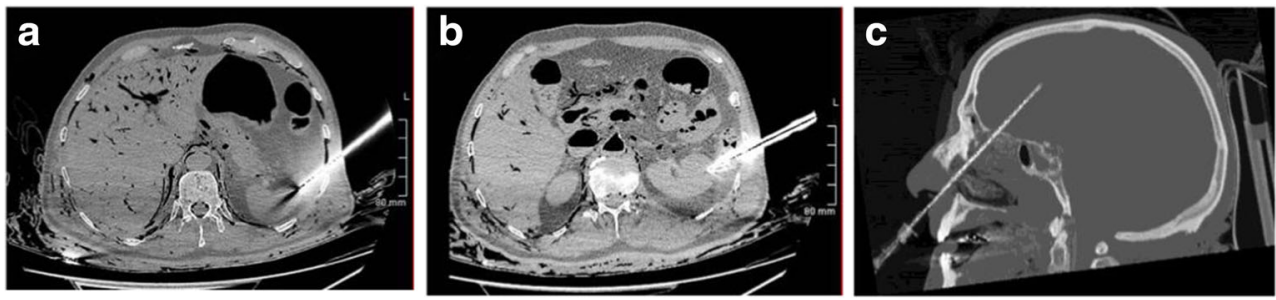

previously published by Rutty et al. [13]. The $250 \mu \mathrm{L}$ of sterile phosphate-buffered saline (PBS), as previously added directly to the Roche Green Beads tubes, was used to suspend the needle biopsy material and rinse any debris from the inside of each sample container. This was then added to the green beads tubes along with $250 \mu \mathrm{L}$ of Roche Bacteria Lysis Buffer before starting the mechanical lysis step and continuing with the DNA extraction and PCR as described in Rutty et al. [13]. For this case, the needle biopsy samples were processed before processing the autopsy tissues and water sample in order to eliminate the possibility of cross-over contamination of the biopsies.

\section{Results}

The results from the needle biopsy and autopsy-derived bacterioplankton PCR analysis are shown in Table 1. This illustrates that for all needle biopsy sites, all three target freshwater bacteria genes were identified. Similar results were observed for the autopsy-derived lung, spleen and brain samples with only one of the genes being identified from the autopsy left kidney and reference water samples.
The PMCT examination (Fig. 3) identified fluid within the paranasal sinuses, lower trachea and bronchi as well as in both pleural cavities. The lungs showed mild ground-glass changes, and the stomach contained low density fluid consistent with water. The right and left atria showed gas distension due to decomposition, so it could not be assessed for heamodilution effects. These features are therefore consistent with drowning, but non-specific and could occur in any PMCT scan.

The autopsy identified external changes appropriate for the time between the deceased disappearance and the autopsy, taking into account the time of year (January) and refrigerated body storage. The body and clothing were all wet at scanning and autopsy. The soles of the feet and palms of the hands showed "washerwoman" changes. The hands and forearms were dirty with silt, and there was silt and dirt staining to the front of the thorax and abdomen. There were no external or internal injuries that could have caused or contributed to death. The middle ear areas showed haemorrhage. The lungs contained fluid as did the stomach. One hundred millimetres of fluid were present to each pleural cavity. There was no evidence of natural disease that could have caused or contributed to death. The toxicology examination identified that there has been social level

Table 1 DNA PCR results from the river, needle biopsy and autopsy-derived tissue samples for freshwater and marine bacterioplankton DNA

\begin{tabular}{|c|c|c|}
\hline Sample type & Freshwater bacterioplankton DNA & Marine bacterioplankton DNA \\
\hline Brain tissue & Aeromonas sp. DNA detected in all three target genes (aerA, gyrB and chiA) & Not detected by PCR \\
\hline Kidney tissue & Weakly positive for one of the three Aeromonas sp. DNA gene targets, gyrB only & Not detected by PCR \\
\hline Spleen tissue & Aeromonas sp. DNA detected in all three target genes (aerA, gyrB and chiA) & Not detected by PCR \\
\hline Lung tissue & Aeromonas sp. DNA detected in all three target genes (aerA, gyrB and chiA) & Not detected by PCR \\
\hline Water from the river & Weakly positive for one of the three Aeromonas sp. DNA gene targets, gyrB only & Not detected by PCR \\
\hline $\begin{array}{l}\text { Needle biopsy } \\
\text { Brain }\end{array}$ & Aeromonas sp. DNA detected in all three target genes (aerA, gyrB and chiA) & Not detected by PCR \\
\hline $\begin{array}{l}\text { Needle biopsy } \\
\text { Left kidney }\end{array}$ & Aeromonas sp. DNA detected in all three target genes (aerA, gyrB and chiA) & Not detected by PCR \\
\hline $\begin{array}{l}\text { Needle biopsy } \\
\text { Spleen }\end{array}$ & Aeromonas sp. DNA detected in all three target genes (aerA, gyrB and chiA) & Not detected by PCR \\
\hline $\begin{array}{l}\text { Needle biopsy } \\
\text { Lung }\end{array}$ & Aeromonas sp. DNA detected in all three target genes (aerA, gyrB and chiA) & Not detected by PCR \\
\hline
\end{tabular}


Fig. 3 PMCT changes. a Fluid within the maxillary and sphenoid sinuses (asterisks). b Fluid within the trachea (asterisk) and bronchi. c Ground-glass opacification in the lungs (within circle). d Pleural effusions (arrows) and air in the cardiac chambers (stars)
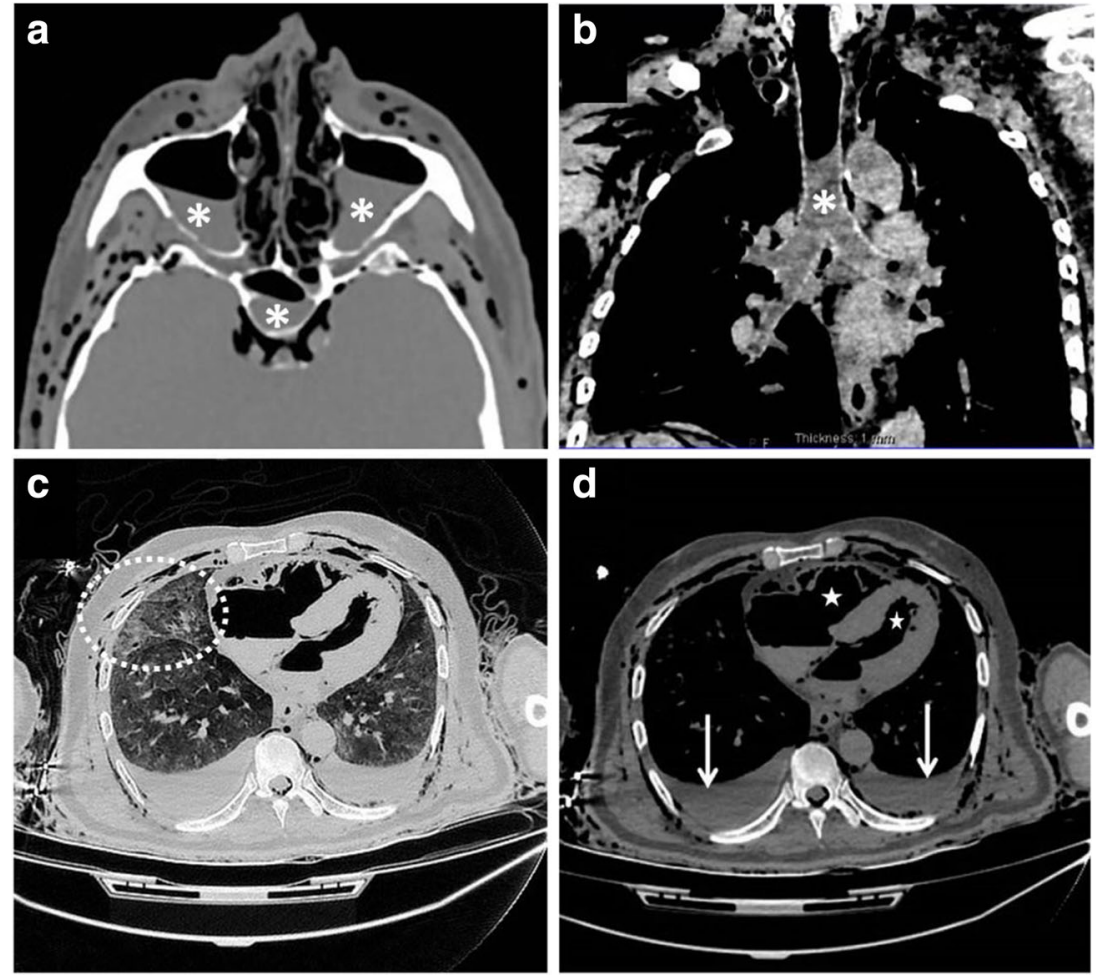

alcohol and therapeutic range citalopram used prior to death. The histology examination showed changes to the lung alveoli consistent with air trapping.

Death was concluded to be as a result of drowning.

\section{Discussion}

The use of cutting needle biopsies with PMCT for diagnostic histological sampling has been previously proposed, principally by the "Virtopsy®" group in Switzerland who, in more recent times, have promoted the use of robotic sampling systems [17-19]. However, in clinical radiology, needle sampling of the tissues of the body for diagnostic purposes is well established. Through this report, we have shown for the first time how such a technique can be used with PMCT for the purposes of providing a minimally invasive approach to the investigation of drowning. The manual sampling was undertaken by a pathologist under the guidance of an interventional radiologist. The training required was minimal to enable accurate organ sampling. We have subsequently trained a radiographer to undertake PMCT-guided cutting needle biopsy.

In this case, four separate isolated organ locations were sampled, i.e. the cranial cavity, left chest cavity, intra- and retro-peritoneal. Unlike at traditional invasive autopsy where the cavities must be opened and organs identified and handled prior to an attempt to undertake sterile sampling [20], the use of PMCT cutting needle biopsies allows for targeted organ sampling. The use of a new needle on each occasion is critical to ensure that cross-contamination does not occur between samples. Manual serial percutaneous biopsies facilitate such an approach. For the autopsy tissue samples, a small section of each tissue is cut for the DNA extraction process. The use of needle biopsies for the bacterioplankton PCR assay also reduced the need to manipulate the tissues, reducing hands-on time in the laboratory and reducing the risk of cross-over contamination during preparation of the samples.

Although a period of time had elapsed between the disappearance and the sampling of the body at PMCT and autopsy, Kakizaki et al. have previously demonstrated that post-mortem bacterial invasion of tissues does not readily occur, even in highly decomposed bodies [21]. Also, although the surface of the body had been exposed to the water, and would be expected to be contaminated with freshwater bacterioplankton, cleaning the skin with alcohol and the use of the coaxial needle, which has been shown to allow clinical sampling of tumours without tumour seeding [22], allowed for organ sampling without the introduction of contaminant from the skin surface during the insertion and withdrawal of the needle.

The question does arise "could contamination of the sample arise because the coaxial system passes through skin surface, water and other tissues prior to reaching the target organ, or as the introducer stylet is removed prior to the sampling". Currently, the answer to this question is unknown. However, considering the design of the coaxial system, we would not expect contamination to occur. The co-axial system is inserted with an introducer blocking the central channel. After introduction, this introducer needle is withdrawn. The sampling needle is 
then inserted so the cutting end extends beyond the previous introducer tip position into the target tissue. The mechanism then advances the bladed needle further into the tissue, the sheath then advances over it cutting a sample, which is be contained within the sampling sheath making a "sterile chamber". As the sampling needle is withdrawn, this tissue remains within this "chamber". The final sample is removed. We do not immerse the needle tip into the tissue-sample preservative fluid, so only the cut sample is added. In this single case, we have shown that the needle biopsy results are comparable to autopsy-derived samples. The observation that the river water sample does not contain all three bacterioplankton can be hypothesised due to differences between the water bacterioplankton populations at the place and time the deceased actually drowned and the sample was taken. Another hypothesis is that bacterioplankton are more dilute free in water whereas the organisms become more concentrated when filtered into the body via the lungs.

This is only a single-case observation, and we accept that there is an unknown risk that due to the use of PCR, bacterioplankton DNA contamination may occur during the sampling process. A larger study is now underway to validate this technique and to consider the issue of potential contamination, which would have wider implications for all PMCT needle biopsy sampling. However, we feel that it is appropriate to present these results and discussion of potential limitations to autopsy and imaging practitioners for consideration and research.

\section{Conclusions}

We present a single case report to illustrate a new diagnostic technical approach of minimally invasive PMCT enhanced by coaxial cutting needle biopsy sampling for bacterioplankton for the diagnosis of drowning. This paper enhances the previous works related to PMCT and drowning. It also raises a risk for those engaged in PMCT biopsy sampling, i.e. sample contamination. By translating CT-guided biopsy method from clinical radiology, we illustrate a simple method which can be undertaken for diagnostic organ sampling for PCR for the diagnosis of drowning.

Compliance with ethical standards The deceased was consented for PMCT research, including core needle biopsy, pulmonary ventilation and targeted limb vessel angiography in accordance with previously published ethics and consenting procedures by the relatives of the deceased.

Conflict of interest The authors declare that they have no conflict of interest.

Open Access This article is distributed under the terms of the Creative Commons Attribution 4.0 International License (http:// creativecommons.org/licenses/by/4.0/), which permits unrestricted use, distribution, and reproduction in any medium, provided you give appropriate credit to the original author(s) and the source, provide a link to the Creative Commons license, and indicate if changes were made.

\section{References}

1. Christe A, Aghayev E, Jackowski C, Thali MJ, Vock P (2008) Drowning-post-mortem imaging findings by computed tomography. Eur Radiol 18:283-290

2. Kawasumi Y, Kawabata T, Sugai Y, Usui A, Hosokai Y, Sato M, Saito H, Ishibashi T, Hayashizaki Y, Funayama M (2012) Assessment of the relationship between drowning and fluid accumulation in the paranasal sinuses on post-mortem computed tomography. Eur J Radiol 81:3953-3955

3. Kawasumi Y, Kawabata T, Sugai Y, Usui A, Hosokai Y, Sato M, Saito H, Ishibashi T, Hayashizaki Y, Funayama M (2013) Diagnosis of drowning using post-mortem computed tomography based on the volume and density of fluid accumulation in the maxillary and sphenoid sinuses. Eur J Radiol 82:e562-e566

4. Raux C, Saval F, Rouge D, Telmon N, Dedouit F (2014) Diagnosis of drowning using post-mortem computed tomography - state of the art. Arch Med Sadowej Kryminol 64:59-75

5. Usui A, Kawasumi Y, Funayama M, Saito H (2014) Postmortem lung features in drowning cases on computed tomography. Jpn J Radiol 32:414-420

6. Filograna L, Tartaglione T, Vetrugno G, Guerra C, Fileni A, Bonomo L (2015) Freshwater drowning in a child: a case study demonstrating the role of post-mortem computed tomography. Med Sci Law 55:304-311

7. Vander Plaetsen S, De Letter E, Piette M, Van Parys G, Casselman JW, Verstraete K (2015) Post-mortem evaluation of drowning with whole body CT. Forensic Sci Int 249:35-41

8. Lo Re G, Vernuccio F, Galfano MC, Picone D, Milone L, La Tona G, Argo A, Zerbo S, Salerno S, Procaccianti P, Midiri M, Lagalla R (2015) Role of virtopsy in the post-mortem diagnosis of drowning. Radiol Med 120:304-308

9. Van Hoyweghen AJ, Jacobs W, Op de Beeck B, Parizel PM (2015) Can post-mortem CT reliably distinguish between drowning and non-drowning asphyxiation? Int J Legal Med 129:159-164

10. Kawasumi Y, Usui A, Sato Y, Sato Y, Daigaku N, Hosokai Y, Hayashizaki Y, Funayama M, Ishibashi T (2015) Distinction between saltwater drowning and freshwater drowning by assessment of sinus fluid on post-mortem computed tomography. Eur Radiol. [Epub ahead of print]

11. Suto M, Kato N, Abe S, Nakamura M, Tsuchiya R, Hiraiwa K (2007) Detection of bacterial genes by PCR and its application to practical cases of death by drowning. Res Pract Forensic Med 50: 73-79 [Japanese with English abstract]

12. Uchiyama T, Kakizaki E, Kozawa S, Nishida S, Imamura N, Yukawa N (2012) A new molecular approach to help conclude drowning as a cause of death: simultaneous detection of eight bacterioplankton species using real-time PCR assays with TaqMan probes. Forensic Sci Int 222:11-26

13. Rutty GN, Bradley CJ, Biggs MJ, Hollingbury FE, Hamilton SJ, Malcomson RD, Holmes CW (2015) Detection of bacterioplankton using PCR probes as a diagnostic indicator for drowning; the Leicester experience. Leg Med (Tokyo) 17:401-408

14. I-Chen T, Wei-Lin T, Min-Chi C, Gee-Chen C, Wen-Sheng T, SiWa C, Clayton Chi-Chang C (2009) CT-guided core biopsy of lung lesions: a primer. Am J Roentgenol 193:5, 1228-1235

15. Saunders S, Amoroso J, Morgan B, Rutty G (2013) Consenting the recently bereaved for post-mortem targeted angiography research; our experience of 207 adult cases. J Clin Pathol 66:326-329

16. Code of practice and performance standards for forensic pathology in England, Wales and Northern Ireland http://www. rcpath.org/Resources/R CPath/Migrated\% 20 Resources/Documents/G/G131_CoPForensicPathology_Oct12. pdf (last visited February 2016) 
17. Aghayev E, Thali MJ, Sonnenschein M, Jackowski C, Dirnhofer R, Vock P (2007) Post-mortem tissue sampling using computed tomography guidance. Forensic Sci Int 166:199-203

18. Ebert LC, Ptacek W, Naether S, Fürst M, Ross S, Buck U, Weber S, Thali M (2010) Virtobot — a multi-functional robotic system for 3D surface scanning and automatic post mortem biopsy. Int J Med Robot 6:18-27

19. Ebert LC, Ptacek W, Breitbeck R, Fürst M, Kronreif G, Martinez RM, Thali M, Flach PM (2014) Virtobot 2.0: the future of automated surface documentation and CT-guided needle placement in forensic medicine. Forensic Sci Med Pathol 10:179-186
20. Collection of microbiology specimens In, The Hospital Autopsy. A manual of fundamental autopsy practice. Eds, Burton JL, Rutty GN. Hodder Arnold, London, 2010 pages 228-229

21. Kakizaki E, Kozawa S, Imamura N, Uchiyama T, Nishida S, Sakai M, Yukawa N (2011) Detection of marine and freshwater bacterioplankton in immersed victims: post-mortem bacterial invasion does not readily occur. Forensic Sci Int 211:9-18

22. Maturen KE, Nghiem HV, Marrero JA, Hussain HK, Higgins EG, Fox GA, Francis IR (2006) Lack of tumor seeding of hepatocellular carcinoma after percutaneous needle biopsy using coaxial cutting needle technique. AJR Am J Roentgenol 187(5):1184-1187 